\title{
Single Phase Matrix Converter for Radio Frequency Induction Heating
}

\author{
N. Nguyen-Quang, D.A. Stone, C.M. Bingham, and M.P. Foster \\ Department of Electronic and Electrical Engineering, University of Sheffield, Mappin Street, Sheffield, S1 3JD, (UK)
}

\begin{abstract}
Conventional converters for radio frequency induction heating usually follow an AC-DC-AC structure, which can exhibit non-unity power factor and introduce large harmonic currents into the utility supply. The need for a direct converter for radio frequency induction heating, featuring unity power factor, and sinusoidal input current, has motivated the development of a single phase matrix converter as an induction heater. A novel commutation strategy is therefore required to ensure smooth operation of the converter whilst creating a high frequency output under soft switching conditions. The operating principle and features of the proposed converter are described here, and experimentally verified.
\end{abstract}

Index Terms--Induction heating, matrix converter, sinusoidal input current, soft switching, unity power factor.

\section{INTRODUCTION}

Radio frequency (R.F.) induction heating requires a high frequency AC power supply, typically 100-200 $\mathrm{kHz}$. However, the conventional AC-DC-AC converter topology makes use of large energy storage components, and requires complicated control algorithms to provide a unity power factor sinusoidal input current $[1,2]$. Both the systems in [1] and [2] make use of a three-phase controlled rectifier as the utility supply interface, and a PLL-based controller for the DC-AC converter. Other systems [3-6] usually assume that a DC power supply is available, requiring power quality improvements for interfacing to the utility supply, as reviewed in $[7,8]$. There have been attempts in improving the power factor and input current waveform of the $\mathrm{AC}-\mathrm{AC}$ converter for induction heating, as reported in $[9,10]$, however, the voltage drop across the switch on turn off may be much higher than the input voltage, which in turn, may limit the system to low frequency applications due to the difficulty of making high-speed, high-voltage devices. In addition, frequency modulation used for power control may cause some EMC problems at high operating frequencies. Recently, matrix converters offering direct AC-AC conversion whilst requiring near-zero energy storage components, have attracted a great deal of attention. Although matrix converters are well-known for synthesizing relatively low frequency outputs from the utility supply [11-15], there remains limited material concerning the use of matrix converters for high frequency applications, viz. induction heating. Generally, as fast switching devices are utilised in matrix converters, it is possible to make a high-frequency matrix converter as reported in this paper.
Here, simulation and experimental results from a single-phase, high-frequency switched matrix converter, employed as an R.F. induction heater, are presented. The converter inherits the simple structure of classic matrix converters, a unity power factor utility supply interface, and a practically sinusoidal input current waveform. In addition, soft switching has been implemented in the converter, which employing a novel switching control pattern.

The next section presents the operating principles of the proposed single phase matrix converter with the new switching control pattern. Section III highlights the features of the proposed topology and switching pattern. In section IV, simulation and experimental results are compared, along with the discussion of those results.

\section{Proposed Topology ANd Principle of Operation}
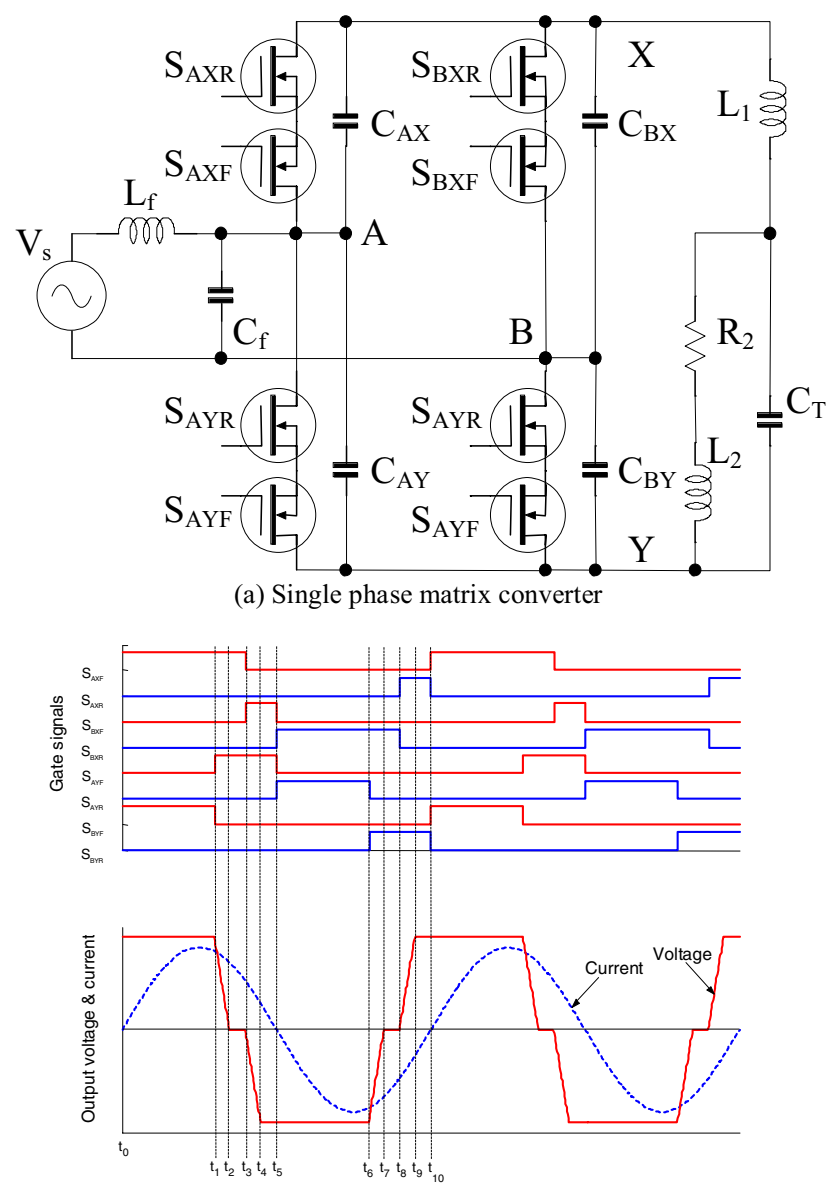

(b) Operation waveforms

Fig. 1. Proposed topology and key operation waveforms 
Fig. 1(a) shows the topology of the proposed single phase matrix converter, whilst Fig. 1(b) presents its key waveforms for a positive half-cycle of input voltage.

The AC input is fed to the converter through a small line filter, comprising of inductor $\mathrm{L}_{\mathrm{f}}$ and capacitor $\mathrm{C}_{\mathrm{f}}$. The converter is a $2 \times 2$ matrix converter, in which each bidirectional switch is implemented using two MOSFETs connected in common source configuration, utilising the built-in diode of the device. Across each bidirectional switch is a commutating capacitor. Capacitors $\mathrm{C}_{\mathrm{AX}}$ and $\mathrm{C}_{\mathrm{BX}}$ have the same value and are associated with the loadcommutated (LC) row. Similarly, $\mathrm{C}_{\mathrm{AY}}$ and $\mathrm{C}_{\mathrm{BY}}$ belong to the pulse-width-modulation (PWM) row. The load is an LLC resonant circuit, where $\mathrm{L}_{1}$ is the series inductor for matching the parallel resonant tank, consisting of workhead inductance $\mathrm{L}_{2}$, reflected load resistance $\mathrm{R}_{2}$ and tank capacitor $\mathrm{C}_{\mathrm{T}}$, with the high frequency voltage source.

Because of the presence of the series inductor $\mathrm{L}_{1}$, a simple explanation of the operating principle can be made by assuming that the load acts as a sinusoidal current sink, and that the devices are ideal. Starting with the load current (output current of the matrix converter) crossing zero and entering its positive half-cycle, the converter will go through the following modes of operation in the positive half-cycle of the input voltage $\left(\mathrm{V}_{\mathrm{AB}}>0\right)$, Fig. 2 .

Mode 1 [ $\left.\boldsymbol{t}_{\boldsymbol{0}}, \boldsymbol{t}_{1}\right]$ : Before this mode, $\mathrm{t}<\mathrm{t}_{0}$, switches $\mathrm{S}_{\mathrm{AXR}}$ and $S_{B Y R}$ are on, creating a path for the load current in its negative half-cycle, and making zero voltage drop on $\mathrm{C}_{\mathrm{AX}}$ and $\mathrm{C}_{\mathrm{BY}}$. The voltage on $\mathrm{C}_{\mathrm{AY}}$ and $\mathrm{C}_{\mathrm{BX}}$ will be the instantaneous input voltage $V_{A B}$. At $t=t_{0}$, both $S_{A X R}$ and $\mathrm{S}_{\mathrm{BYR}}$ are turned off, and switches $\mathrm{S}_{\mathrm{AXF}}$ and $\mathrm{S}_{\mathrm{BYF}}$ are turned on under zero-current and zero-voltage condition. As the current is flowing in the diodes associated with devices, the output voltage equals the input voltage $\mathrm{V}_{\mathrm{AB}}$.

Mode $2\left[t_{1}, t_{2}\right]$ : At some time through the switching cycle, $\mathrm{S}_{\mathrm{BYF}}$ is switched off, and its counterpart in the opposite phase leg, $\mathrm{S}_{\mathrm{AYF}}$, is turned on under zero-current condition, because the built-in diode of $\mathrm{S}_{\mathrm{AYR}}$ has been reversed-biased by the positive voltage drop on $\mathrm{C}_{\mathrm{AY}}$. The load current will therefore charge up $\mathrm{C}_{\mathrm{BY}}$ and discharge $\mathrm{C}_{\mathrm{AY}}$, making the output voltage decrease to zero at $\mathrm{t}=\mathrm{t}_{2}$.

Mode $3\left[t_{2}, t_{3}\right]$ : When $\mathrm{C}_{\mathrm{AY}}$ is fully discharged, the built-in diode of $\mathrm{S}_{\mathrm{AYR}}$ is forward-biased, and the load current will circulate through $\mathrm{S}_{\mathrm{AXF}}$ and $\mathrm{S}_{\mathrm{AYF}}$, making zero output voltage. This condition remains until the load current has almost reached zero, when $\mathrm{S}_{\mathrm{AXF}}$ is turned off at $\mathrm{t}=\mathrm{t}_{3}$.

Mode 4 [ $\left.t_{3}, t_{4}\right]$ : Similarly, $\mathrm{S}_{\mathrm{BXF}}$ will be turned on at zero current when $\mathrm{S}_{\mathrm{AXF}}$ is switched off, causing $\mathrm{C}_{\mathrm{AX}}$ to charge up and $C_{B X}$ to discharge. This will cause the output voltage to further decrease, giving a negative output voltage.

Mode $5\left[\boldsymbol{t}_{4}, \boldsymbol{t}_{5}\right]$ : At $\mathrm{t}=\mathrm{t}_{4}$, when $\mathrm{C}_{\mathrm{BX}}$ is fully discharged, the built-in diode of $\mathrm{S}_{\mathrm{BXR}}$ is forward-biased, and the output current will circulate through $\mathrm{S}_{\mathrm{AYF}}$ and $\mathrm{S}_{\mathrm{BXF}}$, making the output voltage clamped at $-\mathrm{V}_{\mathrm{AB}}$. Just before the current reverses, $\mathrm{S}_{\mathrm{AYF}}$ and $\mathrm{S}_{\mathrm{BXF}}$ are switched off.

Mode $6\left[t_{5}, t_{6}\right]$ : At the same time $\mathrm{S}_{\mathrm{AYF}}$ and $\mathrm{S}_{\mathrm{BXF}}$ are turned off, at $\mathrm{t}=\mathrm{t}_{5}, \mathrm{~S}_{\mathrm{AYR}}$ and $\mathrm{S}_{\mathrm{BXR}}$ are switched on under zero-voltage and zero-current condition. The output voltage equals $-\mathrm{V}_{\mathrm{AB}}$ and the current will circulate through $\mathrm{S}_{\mathrm{AYR}}$ and $\mathrm{S}_{\mathrm{BXR}}$, starting the negative half-cycle.

Mode $7\left[t_{6}, t_{7}\right]$ : Part way through the cycle, $\mathrm{S}_{\mathrm{AYR}}$ is turned off and $\mathrm{S}_{\mathrm{BYR}}$ is switched on, at $\mathrm{t}=\mathrm{t}_{6}$. The load current will then be carried by $\mathrm{C}_{\mathrm{AY}}$ and $\mathrm{C}_{\mathrm{BY}}$, causing the output voltage to increase until it reaches zero, at which time the built-in diode of $\mathrm{S}_{\mathrm{BYF}}$ becomes forward-biased.

Mode $8\left[\boldsymbol{t}_{7}, \boldsymbol{t}_{\boldsymbol{s}}\right]$ : This mode is similar to mode 3 , when the load current circulates through $\mathrm{S}_{\mathrm{BXR}}$ and $\mathrm{S}_{\mathrm{BYR}}$, giving zero output voltage. This condition remains until the output current is almost zero, when $\mathrm{S}_{\mathrm{BXR}}$ switches off, at $\mathrm{t}$ $=\mathrm{t}_{8}$.

Mode 9 [ $\left.t_{\boldsymbol{s}}, t_{9}\right]$ : At the same time $\mathrm{S}_{\mathrm{BXR}}$ is turned off, $\mathrm{S}_{\mathrm{AXR}}$ will be switched on under zero-current condition, causing $\mathrm{C}_{\mathrm{AX}}$ to discharge and $\mathrm{C}_{\mathrm{BX}}$ to charge up. This will cause the output voltage to further increase, giving a positive output voltage.

Mode 10 [ $\left.\boldsymbol{t}_{9}, \boldsymbol{t}_{10}\right]$ : At $\mathrm{t}=\mathrm{t}_{9}$, when $\mathrm{C}_{\mathrm{AX}}$ is fully discharged, the built-in diode of $\mathrm{S}_{\mathrm{AXR}}$ is forward-biased, and the output current will circulate through $\mathrm{S}_{\mathrm{AXR}}$ and $\mathrm{S}_{\mathrm{BYR}}$, making the output voltage clamp at $\mathrm{V}_{\mathrm{AB}}$. Just before the current reverses, $\mathrm{S}_{\mathrm{AXR}}$ and $\mathrm{S}_{\mathrm{BYR}}$ are switched off, and $\mathrm{S}_{\mathrm{AXF}}$ and $\mathrm{S}_{\mathrm{BYF}}$ are turned on under a zero-current and zero-voltage condition, starting a new output cycle.

For the negative half-cycle of input voltage, switches $\mathrm{S}_{\mathrm{AXF}}$ and $\mathrm{S}_{\mathrm{BXF}}, \mathrm{S}_{\mathrm{AYF}}$ and $\mathrm{S}_{\mathrm{BYF}}, \mathrm{S}_{\mathrm{AXR}}$ and $\mathrm{S}_{\mathrm{BXR}}$, and $\mathrm{S}_{\mathrm{AYR}}$ and $S_{B Y R}$ exchange their role, respectively.

As may be seen, in addition to zero-current switching on or zero-voltage zero-current switching on, all the switches are switched off under zero-voltage condition, with the support of commutating capacitors rapidly removing the current from the switches.

\section{FEATURES}

The converter inherits the simple structure of classic matrix converters, and utilises small commutating capacitors, making a more compact construction without any bulky and unreliable electrolytic capacitors.

Operating at high frequency, the converter only requires a small line filter at the interface to the utility supply, resulting in unity power factor sinusoidal input current.

As described in the previous section, soft switching has been implemented in the converter, proposing a new switching control pattern. In line with conventional matrix converters, there are two basic commutation strategies, namely "voltage commutation", which requires the knowledge of the sign of input voltage, and "current commutation", which needs the knowledge of the sign of output current $[12,16]$. These strategies can be made in four-steps or two-steps, requiring little dead time between the steps. The commutation strategy used in the proposed converter falls in the category of voltage commutation, using the sign of the input voltage to select an appropriate switching pattern. The commutation, however, does not need to ensure a path for the inductive load current, owing to the support of the commutating capacitors, and the single-step switching pattern is therefore proposed, as may be seen in Fig. 1(b). 


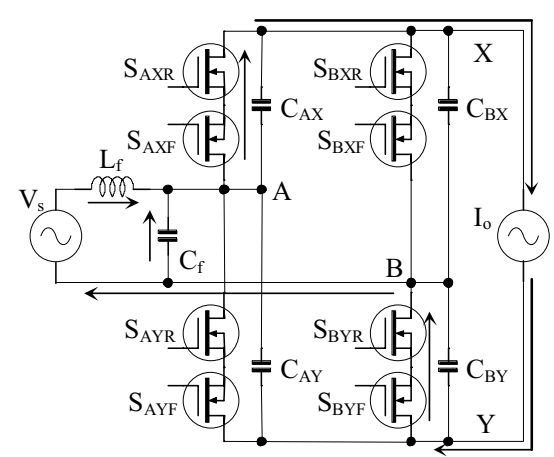

$<$ Mode 1 $>$

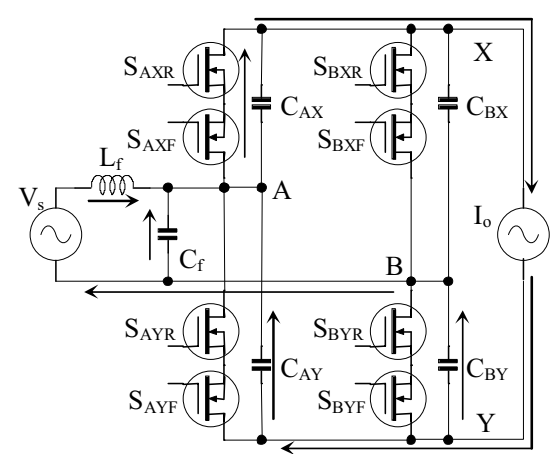

$<$ Mode 2 $>$

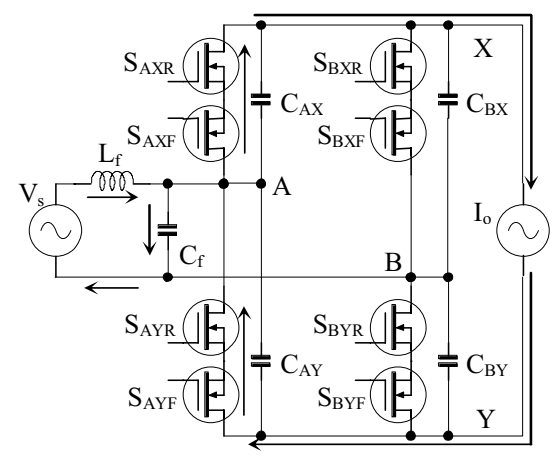

$<$ Mode 3 $>$

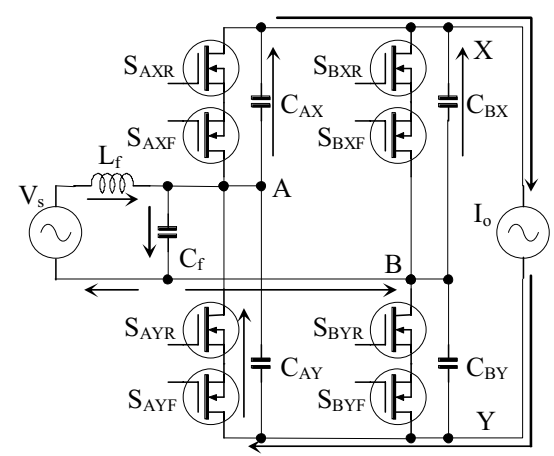

$<$ Mode 4>

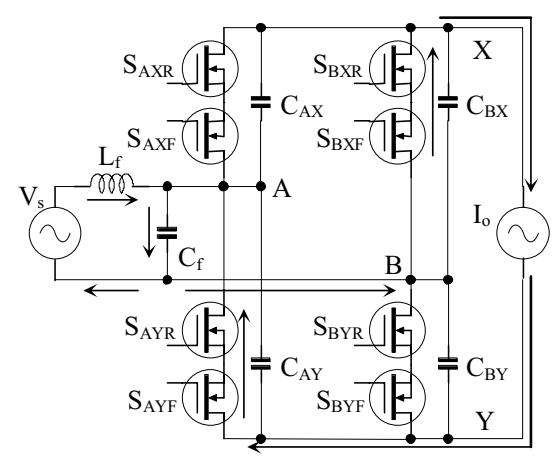

$<$ Mode 5 $>$

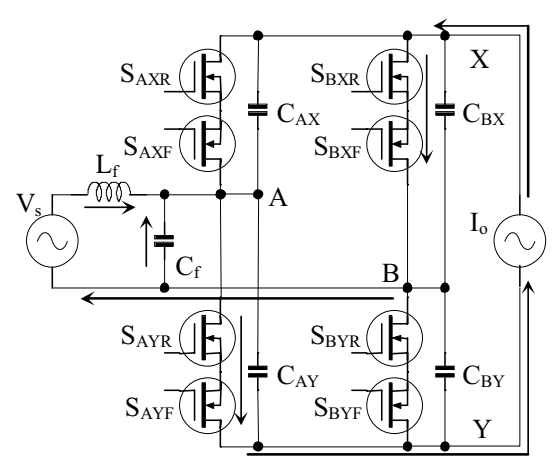

$<$ Mode 6>

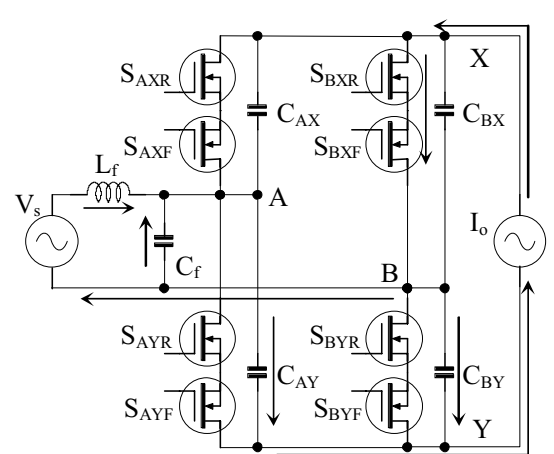

$<$ Mode $7>$

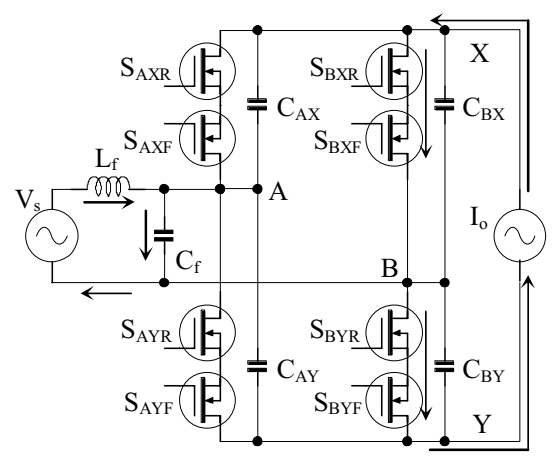

$<$ Mode $8>$

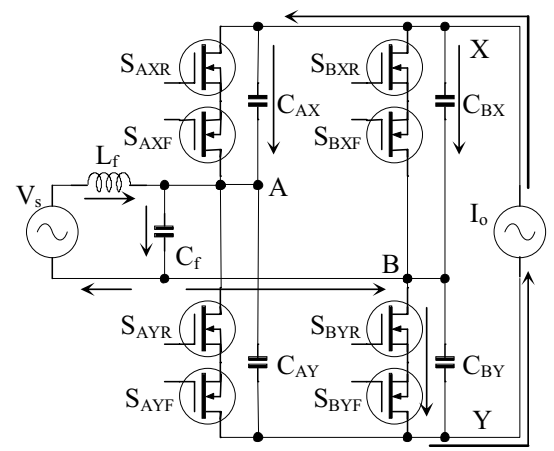

$<$ Mode 9>

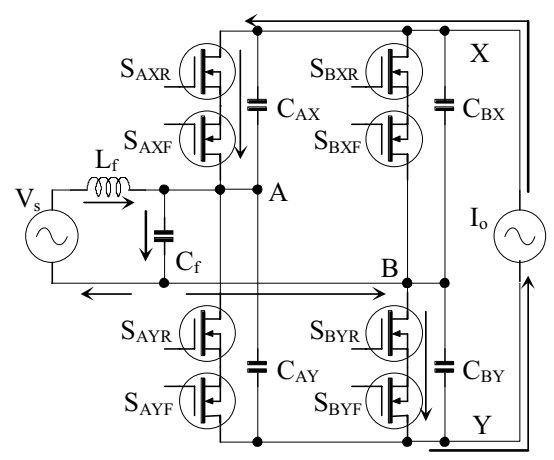

Fig. 2. Operation modes of proposed converter 
The proposed voltage commutation strategy is very simple and can be implemented at no extra cost for additional snubbing components.

It is possible to find an optimal switching angle for the load-commutated row that enables the power control over a wide range under soft switching condition. The power is controlled by varying the switching angle of the pulsewidth-modulation row, instead of varying the switching frequency. This helps reduce the EMC problems associated with the power control method of frequency modulation.

In comparison to other single phase converters for induction heating, the proposed converter, with its new switching control pattern, has the advantages of simple single-stage structure, unity power factor sinusoidal input current, low losses due to soft switching over a wide range of power control.

\section{RESUltS AND DisCUSSIONS}

The proposed converter has been built and tested at input $240 \mathrm{~V}(\mathrm{rms})$ for output powers up to $1000 \mathrm{~W}$. The circuit parameters are: $\mathrm{L}_{\mathrm{f}}=575 \mu \mathrm{H}, \mathrm{C}_{\mathrm{f}}=1 \mu \mathrm{F}, \mathrm{C}_{\mathrm{AX}}=\mathrm{C}_{\mathrm{BX}}$ $=4.7 \mathrm{nF}, \mathrm{C}_{\mathrm{AY}}=\mathrm{C}_{\mathrm{BY}}=10 \mathrm{nF}, \mathrm{L}_{1}=16.4 \mu \mathrm{H}, \mathrm{C}_{\mathrm{T}}=0.2435$ $\mu \mathrm{F}$, the power switch is IXYS-IXFK34N80. The watercooled load has an inductance of $3.6 \mu \mathrm{H}$ and a reflected resistance of $2.35 \Omega$ at a frequency of $182 \mathrm{kHz}$. Fig. 3 is a photograph of the converter with its gate drive boards attached. The input voltage sign detection and the switching control pattern have been implemented on a SPARTAN-3 FPGA board, utilising only $2 \%$ of the resources.

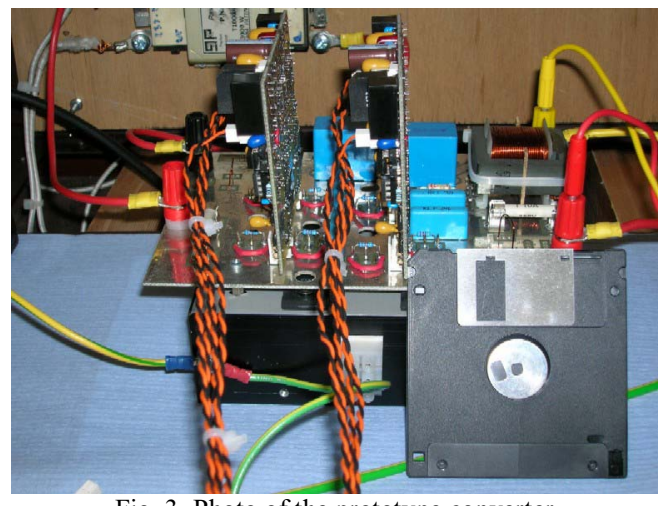

Fig. 3. Photo of the prototype converter
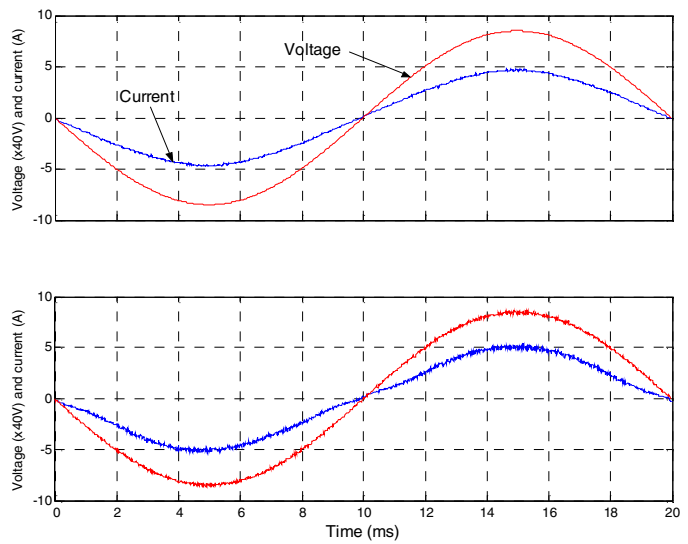

Fig. 4. Simulated (top) and experimental (bottom) input waveforms
In Fig. 4, simulated (in SABER) and experimental input current waveforms for the switching frequency of $182 \mathrm{kHz}$ for a PWM pulse width of $1 \mu \mathrm{s}$, are depicted, showing good agreement. As may be seen, the converter is drawing a practically sinusoidal utility supply current at a unity power factor.

A comparison between simulated (in SPICE) and measured (zoom-in) output waveforms at maximum input voltage, is illustrated in Fig. 5, at the same operating condition as that of Fig. 4.
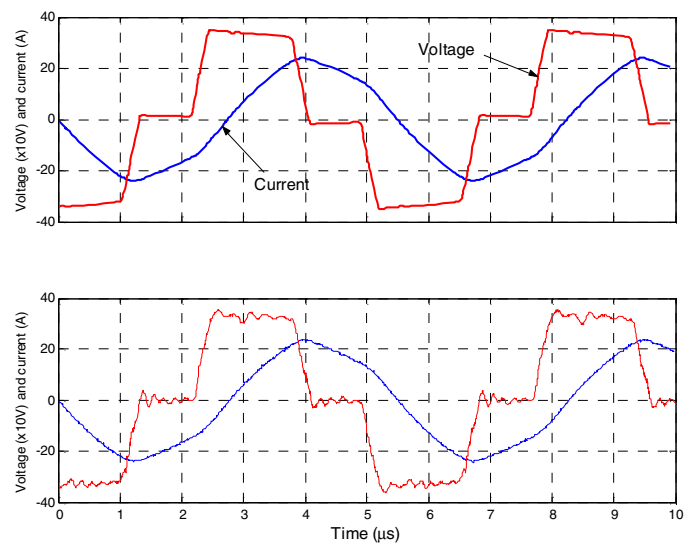

Fig. 5. Simulated (top) and experimental (bottom) cycle-by-cycle output waveforms

Again, it can be seen that the simulated and experimental waveforms are very close.

The power controllability can be seen from the graphs of input current against PWM angle in Fig. 6. Also depicted are the simulated and experimental output current against PWM angle for various switching frequencies.
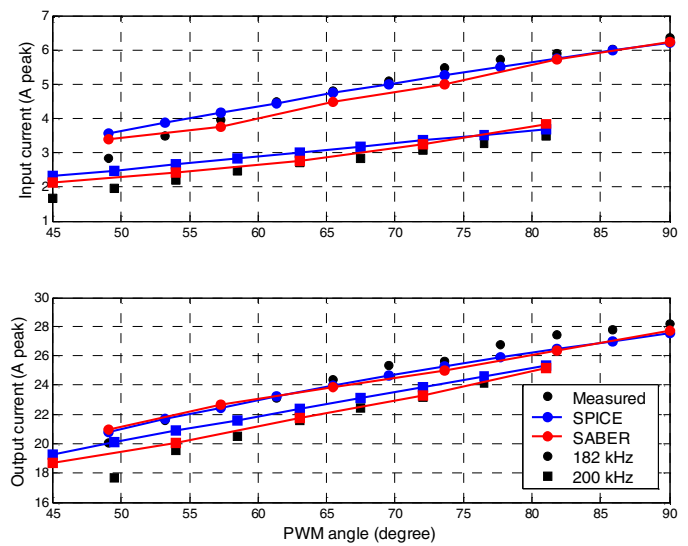

Fig. 6. Input and output currents vs. PWM angle

By combining the power control range of different but very close frequencies, one can obtain a wide range of power control.

Good correlation can also be seen between simulation and experimental data if the input/output current characteristics are examined for a range of frequencies, Fig. 7. 

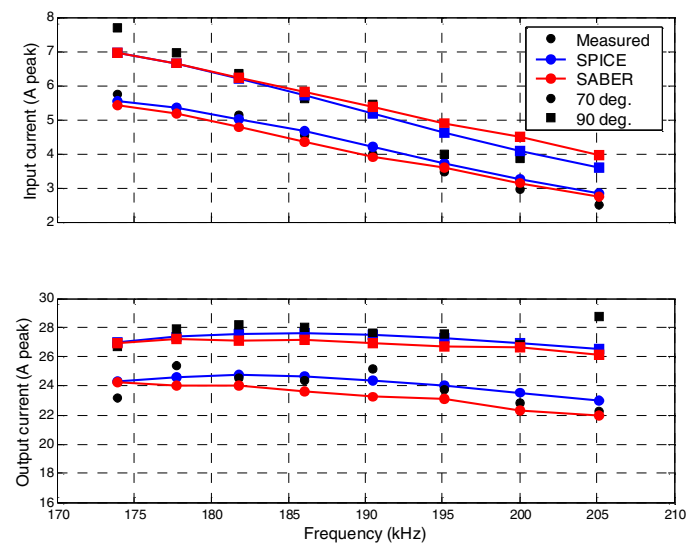

Fig. 7. Input and output currents vs. frequency

Fig. 8 illustrates a typical zero-current and zerovoltage switching condition, where the switch $\mathrm{S}_{\mathrm{AXF}}$ is turned on when the output current is reaching zero and entering its positive half-cycle.

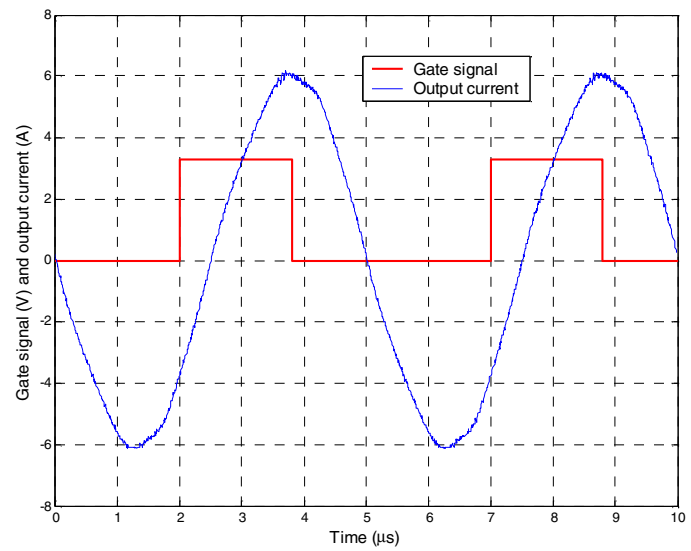

Fig. 8. Typical zero-current switching on

\section{CONCLUSIONS}

Preliminary results from radio frequency induction heater, employing a matrix converter, with unity power factor, and sinusoidal input current, have been presented. The proposed topology and switching pattern ensure soft switching over a wide range of power control. The proposed single-step voltage commutation is very simple and has been implemented without any additional components. It is therefore possible to make a direct converter for induction heating, without having any significant impact on the utility supply, and with the advantages of simple structure, and low losses.

\section{REFERENCES}

[1] Bayindir, N.S.; Kukrer, O.; Yakup, M.: DSP-based PLLcontrolled $50-100 \mathrm{kHz} 20 \mathrm{~kW}$ high-frequency induction heating system for surface hardening and welding applications. IEE Proc.-Electr. Power Appl., Vol. 150, No. 3, May 2003, pp. 365-371.
[2] Okuno, A.; Kawano, H.; Sun, J.; Kurokawa, M.; Kojina, A.; Nakaoka, M.: Feasible development of soft-switched SIT inverter with load-adaptive frequency-tracking control scheme for induction heating. IEEE Trans. Ind. Applicat., Vol. 34, No. 4, July/August 1998, pp. 713-718.

[3] Kifune, H.; Hatanaka, Y.; Nakaoka, M.: Cost effective phase shifted pulse modulation soft switching high frequency inverter for induction heating applications. IEE Proc.-Electr. Power Appl., Vol. 151, No. 1, January 2004, pp. 19-25.

[4] Ogiwara, H.; Nakaoka, M.: ZCS high frequency inverter using SIT for induction heating applications. IEE Proc.Electr. Power Appl., Vol. 150, No. 2, March 2003, pp. 185-192.

[5] Mollov, S.V.; Theodoridis, M.; Forsyth, A.J.: High frequency voltage-fed inverter with phase-shift control for induction heating, IEE Proc.-Electr. Power Appl., Vol. 151 , No. 1, January 2004, pp. 12-18.

[6] Ogiwara, H.; Gamage, L.; Nakaoka, M.: Quasiresonant soft switching $P W M$ voltage-fed high frequency inverter using SIT for induction heating applications. IEE Proc.Electr. Power Appl., Vol. 148, No. 5, September 2001, pp. 385-392.

[7] Singh, B.; Singh, B.N.; Chandra, A.; Al-Haddad, K.; Pandey, A.; Kothari, D.P.: A review of single-phase improved power quality $A C-D C$ converters. IEEE Trans. Ind. Electron., Vol. 50, No. 5, October 2003, pp. 962-981.

[8] Singh, B.; Singh, B.N.; Chandra, A.; Al-Haddad, K.; Pandey, A.; Kothari, D.P.: A review of three-phase improved power quality $A C-D C$ converters. IEEE Trans. Ind. Electron., Vol. 51, No. 3, June 2004, pp. 641-660.

[9] Shenkman, A.; Axelrod, B.; Berkovich, Y.: Single-switch $A C-A C$ converter with high power factor and soft commutation for induction heating applications. IEE Proc.-Electr. Power Appl., Vol. 148, No. 6, November 2001, pp. 469-474.

[10] Shenkman, A.; Axelrod, B.; Berkovich, Y.: Improved modification of the single-switch $A C-A C$ converter for induction heating applications. IEE Proc.-Electr. Power Appl., Vol. 151, No. 1, January 2004, pp. 1-4.

[11] L. Gyugyi and B. R. Pelly: Static Power Frequency Changers. New York: Wiley, 1976.

[12] Wheeler, P.W.; Rodriguez, J.; Clare, J.C.; Empringham, L.; Weinstein, A.: Matrix Converters: A Technology Review. IEEE Trans. Ind. Electron., Vol. 49, No. 2, April 2002, pp. 276-288.

[13] Kim, S.; Sul, S.-K.; Lipo, T.A.: AC/AC Power Conversion Based on Matrix Converter Topology with Unidirectional Switches. IEEE Trans. Ind. Appl., Vol. 36, No. 1, January/February 2000, pp. 139-145.

[14] Mutschler, P.; Marcks, M.: A Direct Control Method for Matrix Converters. IEEE Trans. Ind. Electron., Vol. 49, No. 2, April 2002, pp. 362-369.

[15] Zhang, L.; Watthanasarn, C.; Shepherd, W.: Analysis and comparison of control techniques for $A C-A C$ matrix converters. IEE Proc.-Electr. Power Appl., Vol. 145, No. 4, July 1998, pp. 284-294.

[16] Mahlein, J.; Igney, J.; Weigold, J.; Braun, M.; Simon, O: Matrix converter commutation strategies with and without explicit input voltage sign measurement. IEEE Trans. Ind. Electron., Vol. 49, No. 2, April 2002, pp. 407-414. 